\title{
Agroecology and Sustainable Agriculture
}

In the framework of the $16^{\text {th }}$ National Meeting of the Italian Ecological Society ("Global Change, Ecological Diversity and Sustainability", University of Tuscia, Viterbo, 19-22 September 2006), a symposium was devoted to "Agroecology and Sustainable Development". A major goal of this symposium was to contribute to keeping the dialogue among the experts of the various disciplines alive.

Sustainability of agriculture is a challenge for society world wide. Universities and society as a whole have a responsibility in re-examining current perception of nature, of the world and of human society in the light of natural resources depletion, increasing pollution and social inequalities. The urgency to address sustainability issues is increasingly being reflected in the manner in which institutions of higher education around the world are giving priority to the teaching, research and practice of sustainability. The University of Tuscia is involved in international initiatives concerning teaching and research in Agroecology and Sustainable Agriculture. This task requires a transdisciplinary attitude in order to integrate different fields of knowledge and inquiry which usually are strictly separate in the structure of current institutions for education and research. One of the most powerful examples of an integrative approach is the systems paradigm, which calls for a change from a discipline to a systems focus. The systems paradigm is an achievement of both philosophy (process thought) and science (systems thought), although the connections between these two fields of inquiry are usually neglected in both educational curricula and research. Agroecology is a transdisciplinary field of inquiry that can act as both a scientific and epistemological tool for promoting knowledge and understanding appropriate for developing a theory and practice of sustainable development.

The sequence of contributions presented in this issue reflects the symposium's structure, which provided three main reports on Agroecology as a science of integration and shorter communications organised in sub-groups, according to the hierarchy of agroecosystem levels, i.e. landscape, farm, crop and field.

I am very indebted to the Italian Society of Agronomy for the permission to publish the symposium's proceedings in the Italian Journal of Agronomy.

Fabio Caporali

Symposium's Chairman 